\title{
ARTICLE \\ Long Term Spatio-temporal Variations of Seasonal and Decadal Aridity in India
}

\author{
Pavan Kumar B $^{1}$ Bhavani Pinjarla $^{2^{*}}$ P K Joshi $^{3} \quad$ P S Roy $^{4}$ \\ 1. International Crops Research Institute for the SemiArid Tropics, Hyderabad, 502324, India \\ 2. International Maize and Wheat Improvement Center (CIMMYT), New Delhi, 110012, India \\ 3. School of Environmental Sciences (SES), Special Center for Disaster Research (SCDR), Jawaharlal Nehru \\ University (JNU), New Delhi, 110067, India \\ 4. World Resources Institute India, New Delhi, 110016, India
}

\section{ARTICLE INFO}

Article history

Received: 19 July 2021

Accepted: 9 August 2021

Published Online: 12 August 2021

\section{Keywords:}

Aridity index

Aridity index anomaly

NDVI

Potential evapotranspiration

Precipitation

SPI

\begin{abstract}
A comprehensive analysis of climate data (1958-2018) is carried out at the national scale in India to assess spatiotemporal variation in aridity. The aridity is analyzed using UNEP (United Nations Environment Programme) Aridity Index (AI), which is the ratio between Precipitation (P) and Potential Evapotranspiration (PET). Freely available Terra-Climate database, $\mathrm{P}$ and PET variables, offered an unprecedented opportunity for monitoring variations in AI and aridity index anomalies (AIA) at interseasonal and inter-decadal basis. The study also assesses longer term patterns of $\mathrm{P}$ and $\mathrm{AI}$ anomalies with vegetation anomalies. The results indicate that significant clustered areas with maximum dryness are located at west-central part of India, the state of Maharashtra. Overall, there is a gradual increase in the extent of arid zone during 60-year period and spatially maximum extent of percentage change in aridity area is observed. The change patterns of AI in India are largely driven by the changing patterns of precipitation. The maximum impact of decline in precipitation on AIA was observed during Kharif season frequently, for every 4-5 years during 1972-1992. The pattern repeated in the last few recent years (20132018), the decline in precipitation resulted increased aridity. The study also reveals that the availability and usage of irrigation sources have increased from 2014 to 2018. Thus, despite of less precipitation positive vegetation has been resulted in this period. The findings are important to understand the impacts of climate change on land use pattern, and land and water resource management.
\end{abstract}

\section{Introduction}

India is an agrarian country with two-third of its population depending on agriculture and allied activities. It stands the first among the rain-fed agricultural countries of the world ${ }^{[1]}$ with about 61 per cent of farmers relying on rain-fed agriculture. Half of the gross cropped area in India under rain-fed farming ${ }^{[2]}$ and is the second largest producer of rice and wheat, staple food for millions of the world (FAO, 2020). The agriculture productivity primarily depends on climatic factors, namely, precipitation, temperature and evapotranspiration ${ }^{[3,4]}$. The precipitation

*Corresponding Author:

Bhavani Pinjarla,

International Maize and Wheat Improvement Center (CIMMYT), New Delhi, 110012, India;

Email:B.Pinjarla@cgiar.org 
(P), i.e., the quantity of rainfall, its intensity, and its distribution over an area during each cropping season can define the economy of any agriculture dependent country like India ${ }^{[5]}$. The precipitation and its pattern are also important for gaining an understanding of the micro-level availability of water, which in turn is useful for planning agricultural activities, and land and water development activities for future use ${ }^{[6]}$. Potential Evapotranspiration (PET) is the rate at which evapotranspiration occurs from a large area that is completely and uniformly covered with growing vegetation that has access to an unlimited supply of soil water, without advection or heat storage effects ${ }^{[7-}$ 9]. P and PET can collectively affect the availability of water spatially and temporally ${ }^{[10]}$ impacting society and ecosystems ${ }^{[1]}$. The relationship with these two climatic factors informs about degree of aridity in the given area. Here, aridity index (AI) is an indicator of degree dryness of the climate at a given location, which is generally calculated as mathematical measures of P (long-term average water supply) and PET (long-term average water demand). This depends on six climatic factors, namely, maximum air temperature, precipitation, actual vapor pressure, actual solar radiation, minimum air temperature and wind speed ${ }^{[12]}$. Studying AI and its anomalies (Aridity Index Anomaly - AIA) are like monitoring climate variability and its impact on vegetation. The study of these indices is a good tool that policy makers can use to plan agricultural activities, and the use of water resource ${ }^{[13]}$ and its management.

The United Nations Environmental Programme ((UNEP, 1993) defined AI as the ratio of the annual P to the total PET. The high- spatial and temporal resolution Terra Climate dataset has information on various climate variables (both primary and secondary) such as $\mathrm{P}$ and PET at a global scale. The monthly datasets of Terra Climate are useful in aridity and other drought index studies ${ }^{[12]}$. McKee et al. ${ }^{[15,16]}$. ${ }^{[17]}$ developed Standardized Precipitation Index (SPI) a drought index which is simple, easy to calculate and statistically relevant and meaningful. It depends on a single meteorological element, i.e. P, hence flexible and temporally versatile ${ }^{[18,19]}$. Similarly, the impact of climatic variability on the vegetation can be measured using various remote sensing indices. For example, Normalized Difference Vegetation Index (NDVI) ${ }^{[20]}$ is used most often for monitoring vegetation during growing seasons because of its good correlation with crop productivity ${ }^{[21,22]}$. Similarly, Enhanced Vegetation Index (EVI) was developed as an alternative vegetation index to address some of the limitations of the NDVI ${ }^{[23]}$. The Moderate Resolution Imaging Spectro-radiometer (MODIS) provides these vegetation indices fortnightly that are useful in anomaly studies. The NDVI anomaly can be studied along with meteorological indices (AIA and SPI) to characterize drought related impacts on growing vegetation at timescales from month to year ${ }^{[24-27]}$.

The primary objective of the research is to understand distribution of aridity, ranging from month to season, to year across India using Terra Climate (1958-2018) data. The spatio-temporal changes in aridity are assessed using data for 1958-1968 and 2008-2018. To understand the seasonal pattern (aridity anomalies, drought anomalies and vegetation anomalies), State of Maharashtra is taken as a case study, where MODIS-NDVI (2000-2008) anomalies are analyzed with AI and SPI (monthly precipitation and PET data of Terra Climate). These anomalies are compared with agriculture and irrigation data sources. Maharashtra is known for dependence of around 55\% of population on agriculture and its allied activities ${ }^{[28,17]}$. The region has a history of drought ${ }^{[29]}$ and is in a constant state of drought since the year 2012 with deficits in rainfall after every 5-6 years ${ }^{[30,31]}$.

\section{Study Area and Data Used}

\subsection{Study Area}

India is a tropical country situated between $06^{\circ} 44^{\prime}$ and $37^{\circ} 30^{\prime}$ north latitude and $68^{\circ} 7^{\prime}$ and $97^{\circ} 25^{\prime}$ east longitude, covering an area of $3,287,263 \mathrm{~km}^{2}$. The country depicts heterogeneous climatic variation with Himalayan arc in the north, Indian Ocean in south, Arabian Sea in southwest, and the Bay of Bengal in its southeast. The country can be divided into six aridity classes, namely, hyper-arid, arid, semi-arid, dry sub-humid, moist sub-humid and humid. About 15.8\% (50.8 Mha) of the geographic area is arid and nearly $37.6 \%$ (123.4 Mha) is characterized by semi-arid climatic conditions. Different types of crops are adapted to the natural climate in their respective zones. Over $75 \%$ of the cropped area of India falls in the semi-arid tropics (131 million ha out of 174 million ha), which is regularly hit by drought. Both hot and cold arid zones are found in India. In the cold arid zones, the precipitation is low, the vegetation is scattered, and the PET is even as low as zero. Thus, AI values cannot be determined in the cold arid zones. So in this study only the hot arid zone of India (Figure 1) is considered to analyze aridity and its anomalies.

For the study of NDVI, AI and SPI anomalies, state of Maharashtra is taken as a case study. It is situated between $15^{\circ} 44^{\prime}$ and $22^{\circ} 6^{\prime}$ north latitude and $72^{\circ} 36^{\prime} \mathrm{E}$ to $80^{\circ} 54^{\prime}$ east longitude. Around $83 \%$ of the state is characterized by semi-arid climatic condition ${ }^{[31]}$. The western boundary is a narrow string of dry and moist sub-humid zones between semi-arid and Ghat region. The Konkan and the 
Ghat regions are humid and per-humid respectively. Onethird of Maharashtra receives scanty rainfall. This area constitutes $24 \%$ of the drought prone area of India ${ }^{[32]}$. Several region-wide droughts of moderate to extreme intensity were experienced in Maharashtra between 1871 and 2016, which have adversely affected the agricultural crops ${ }^{[31,33]}$. The state accounts for about $9.3 \%$ of India's population (2011) and $11.6 \%$ of gross cropped area (2015-16). Only $18 \%$ of the cropped area, which is predominantly rain-fed, is irrigated. In the state, the share of agriculture and allied sectors declined from $26.01 \%$ to $17.90 \%$ during $1960-61$ to $1990-91$ respectively and further to $9.9 \%$ in $2018-19^{[34]}$. Considering the challenges involved, only agricultural land was studied in the present work.

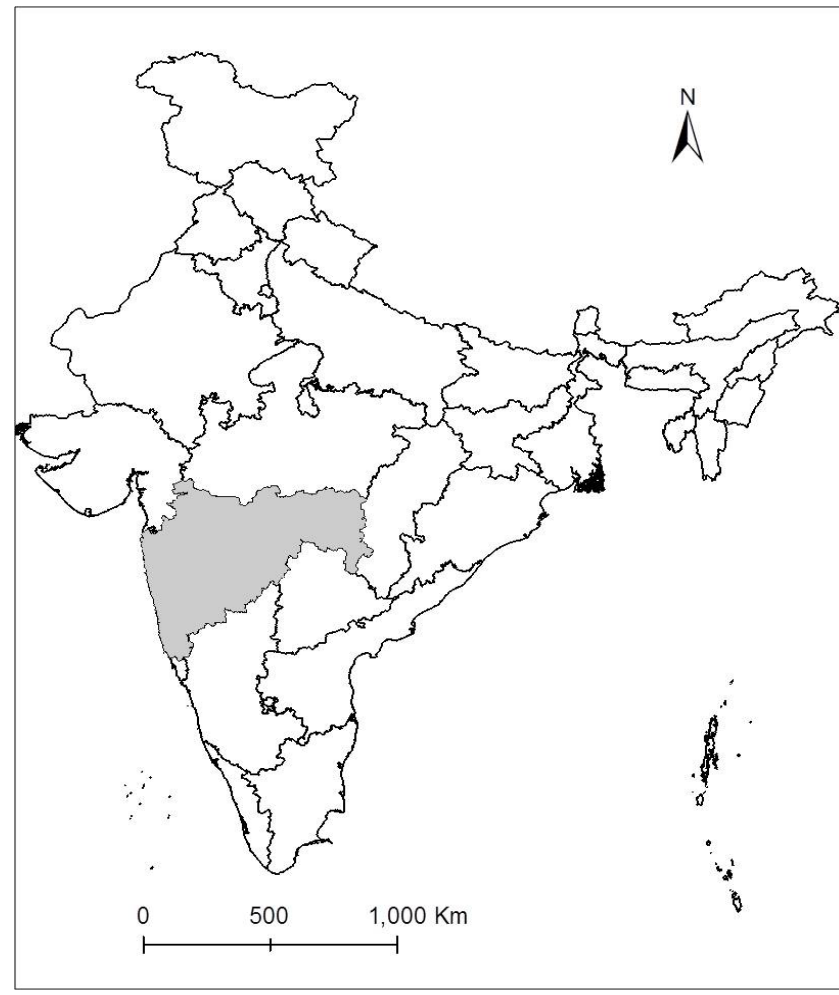

Figure 1. Location of the Study Area. Regional level analysis is done for entire India and local level analysis is done for state of Maharashtra show in grey shade

\subsection{Data Used}

This study used two types of datasets (i) climate data and (ii) remote sensing data.

\subsubsection{Climate data}

The meteorological data (P and PET) were downloaded using Google Earth Engine (GEE) platform from Terra Climate database with spatial resolution of $\sim 4 \mathrm{~km}$ for a period of 60 years $(1958-2018)^{[14]}$. These datasets were used to compute AI, AIA, and SPI; over entire India. These were also used to assess the aridity and relationship with precipitation and vegetation indices (NDVI; NDVI Dev) over the state of Maharashtra.

\subsubsection{Remote sensing data}

MODIS NDVI (MOD13Q1) product with spatial resolution of $250 \mathrm{~m}$ generated every 16 days was obtained from LPDAAC (https://lpdaac.usgs.gov) for the years 2000-2018. It was processed using MODIS Reprojection Tool (MRT). Land Use Land Cover (LULC) map of the year $2005^{[35]}$ was used to extract agricultural area and other areas were masked out.

\subsection{Methodology}

The methodology is organized in two sections. The first section describes calculation of assessment of aridity index anomaly and seasonal long-term (60 years) pattern of aridity anomaly across India. The second section describes seasonal patterns of AIA, NDVI anomaly, and SPI.

\subsubsection{Aridity Index Anomaly (AIA) and decadal changes}

The monthly AI was computed using Terra Climate monthly variables i.e., $\mathrm{P}$ and PET for the period 19582018 while applying the UNEP (United Nations Environment Programme) Aridity Index (AI) (= ratio of P and PET) (UNEP, 1993). The monthly AI data (for 19582018) was staked forming altogether 720 layer (60 years $\times$ 12 months) database. These AI layers were used to generate AIA [ $=$, where, is the long-term (60-year) mean AI and is the AI layer of the year (1958-2018)]. To carry the inter-seasonal and inter-decadal studies, these monthly AI and AIA layers were converted to seasonal (monsoon, winter, and summer, where each season consist of 60 layers), annual and decadal dataset. The spatial change detection of AI maps for monthly, seasonal, and decadal over regional and local scales (India and Maharashtra, respectively) and hot spot analysis was carried using ArcGIS (Getis-Ord Gi*) tools. AI values were classified into six classes based on UNEP ${ }^{[36,17]}$, i.e., Hyper-arid (HA) $(\mathrm{AI}<0.05)$, Arid (A) $(0.05 \leq \mathrm{AI}<0.20)$, Semi-Arid (SA) $(0.20 \leq \mathrm{AI}<0.50)$, Dry sub-Humid (DsHu) $(0.50 \leq$ $\mathrm{AI}<0.65)$, and Humid $(\mathrm{Hu})(\mathrm{AI} \geq 1)$. The resulted hot and cold spots were classified into seven categories based on their Gi Bin values: Hotspot (HS) 99\% significant, HS 95\% significant, HS 90\% significant, not statistically significant, cold spot (CS) 90\% significant, CS 95\% significant, and CS $99 \%$ significant ${ }^{[37]}$. The temporal 
variation plots and change in area and percentage of total arid area were carried out by extracting statistical values of AI and AIA using R software and ArcGIS tools.

\subsubsection{Seasonal patterns analysis of AIA, NDVI anomaly, and Standardized Precipitation Index (SPI)}

The seasonal pattern of AIA along with SPI is carried out to assess the impact on agriculture over extremely significant hot spot regions of aridity. The AIA for the year 2000-2018 was computed using the methodology as explained in the earlier section. For the computation of NDVI anomaly and SPI the following methods were used.

\subsubsection{NDVI anomaly}

MODIS NDVI products of $250 \mathrm{~m}$ resolution produced fortnightly were downloaded from the LPDAAC data pool. The dataset was re-projected with the WSG84 datum. The fortnightly NDVI products were transformed into monthly data by selecting the maximum NDVI of each month from 2000 to 2018. These monthly NDVI data were stacked in sequence for each month. The masking out of the non-agricultural area was carried out using the agriculture area (cropland and fallow land) from the LULC map of the year $2005^{[35]}$ to prepare MODIS agricultural NDVI files. The monthly NDVI files were used to generate the NDVI anomaly [ $=$, where, is the mean NDVI and is the NDVI layer for each month of the year (2000-2018)].

\subsubsection{Standardized Precipitation Index (SPI)}

The SPI is a drought index representing the probability of occurrence of the observed rainfall at a location compared with a long-term reference period. The monthly precipitation data were stacked for the period from 2000 to 2018. The mean and standard deviation of these layers were calculated using the ERDAS software package. The monthly precipitation data were used to calculate the SPI [=, where, and represent the $i^{\text {th }}$ value and the mean value and $\sigma$ represents the deviation from the mean value]. The non-agricultural area was masked out from the monthly (2000-2018) SPI layers

The AI anomaly, NDVI anomaly, and SPI were determined for three seasons: the summer monsoon (June-September), winter (October-January) and summer (February-May) as the mean values of the months of each season. The seasonal files were extracted using the R software package (http://openwetware.org/wiki/ $\mathrm{R}$ _Statistics). The overall methodology of this study is illustrated in Figure $2(a, b)$.
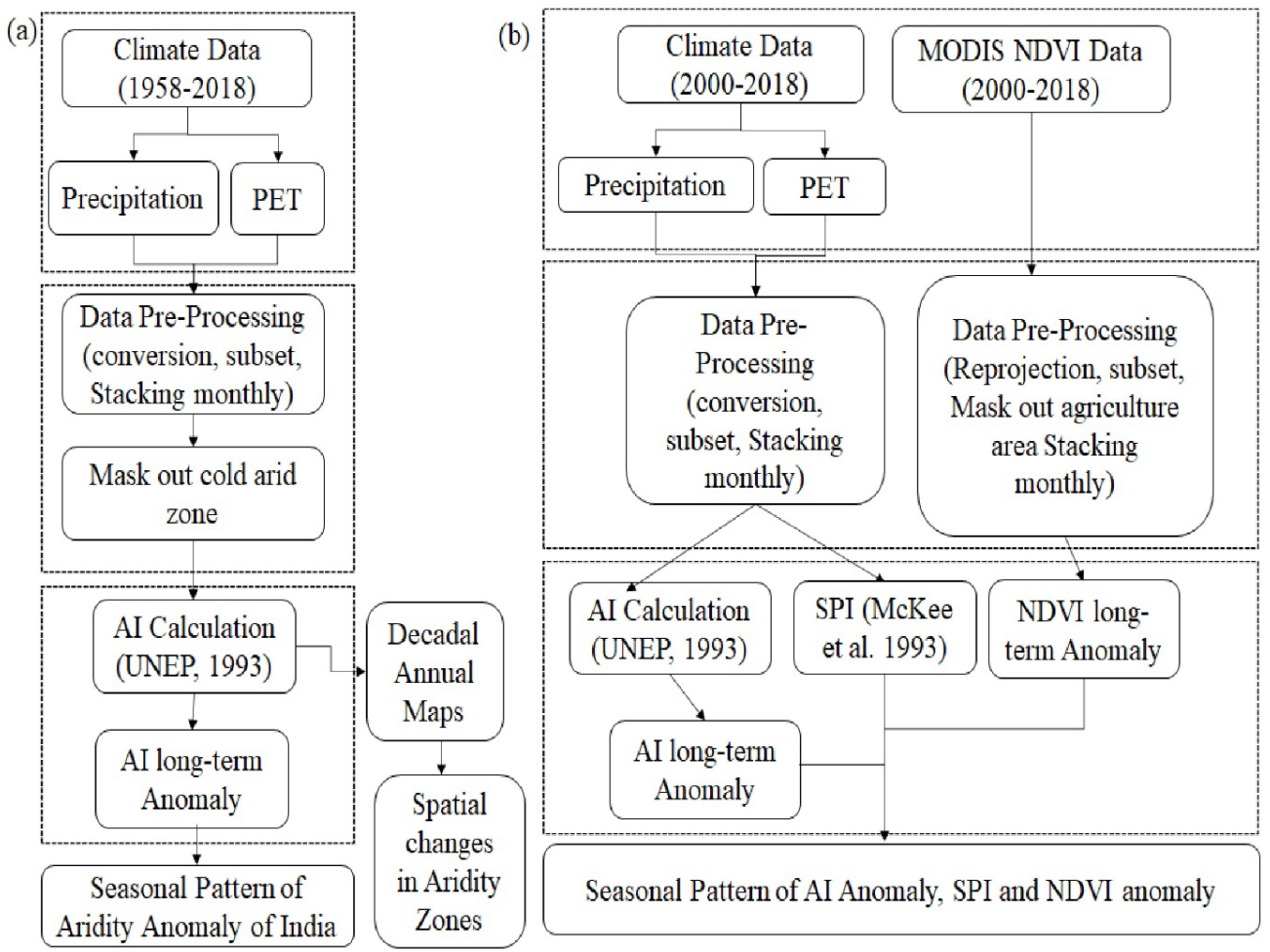

Figure 2. Schematic diagram of approach used for (a) long-term aridity anomaly and decadal changes in arid zones in India, and (b) seasonal analysis of aridity anomaly, SPI and NDVI anomaly 


\section{Results}

Climate parameters play an important role in deciding the aridity over a region, and the quality of precipitation and PET performs an essential position in terms of understanding the extent and scale of aridity over the region. The AI, which is an indicator of degree of dryness, was analyzed for temporal (monthly, seasonal, decadal and sixty year) and spatial changes in arid zones. The AI was spatially analyzed to identify significant hot spot arid region and the impact of climate and aridity variation on agricultural regions.

\subsection{Seasonal Pattern of AIA (1958-2018)}

The seasonal patterns of AIA are explained by bisecting the monthly into seasonal pattern i.e., monsoon (JuneSeptember), winter (October-January) and summer (February-May) to understand the seasonal variability over India (Figure $3 \mathrm{a}-\mathrm{c}$ ). The temporal patterns were inferred, by comparing the frequency (number of years) of negative AIA (more than 2 months in each season) between 1958-92 and 1993-2018 years. During monsoon, frequency of negative AIA is the maximum in the last 25 years compared to 1958-1992. This indicates that the region is turning to dryer. Extreme dryness is observed during the year 2002-03 (Figure 3a). During winter, the fluctuation of aridity level is noticed for the year 19581992, whereas the magnitude of aridity is extreme in the beginning of October month, followed by end of January month in sixty years. The consistent increasing trend in aridity is observed in the last 18 years (2000-2018), except the years 2005-06, 2010-11 and 2013-14. And for summer, the maximum number of years showed negative AIA during 1958-1992 (Figure 3 b-c).

\subsection{Long Term (1958-2018) Pattern of AIA with Precipitation Anomaly}

The long-term (1958-2018) analysis, monthly precipitation and PET data were used, and the mean seasonal and annual AIA anomaly with annual precipitation anomaly was assessed at regional level of India (Figure 4). Analysis of Seasonal AIA with
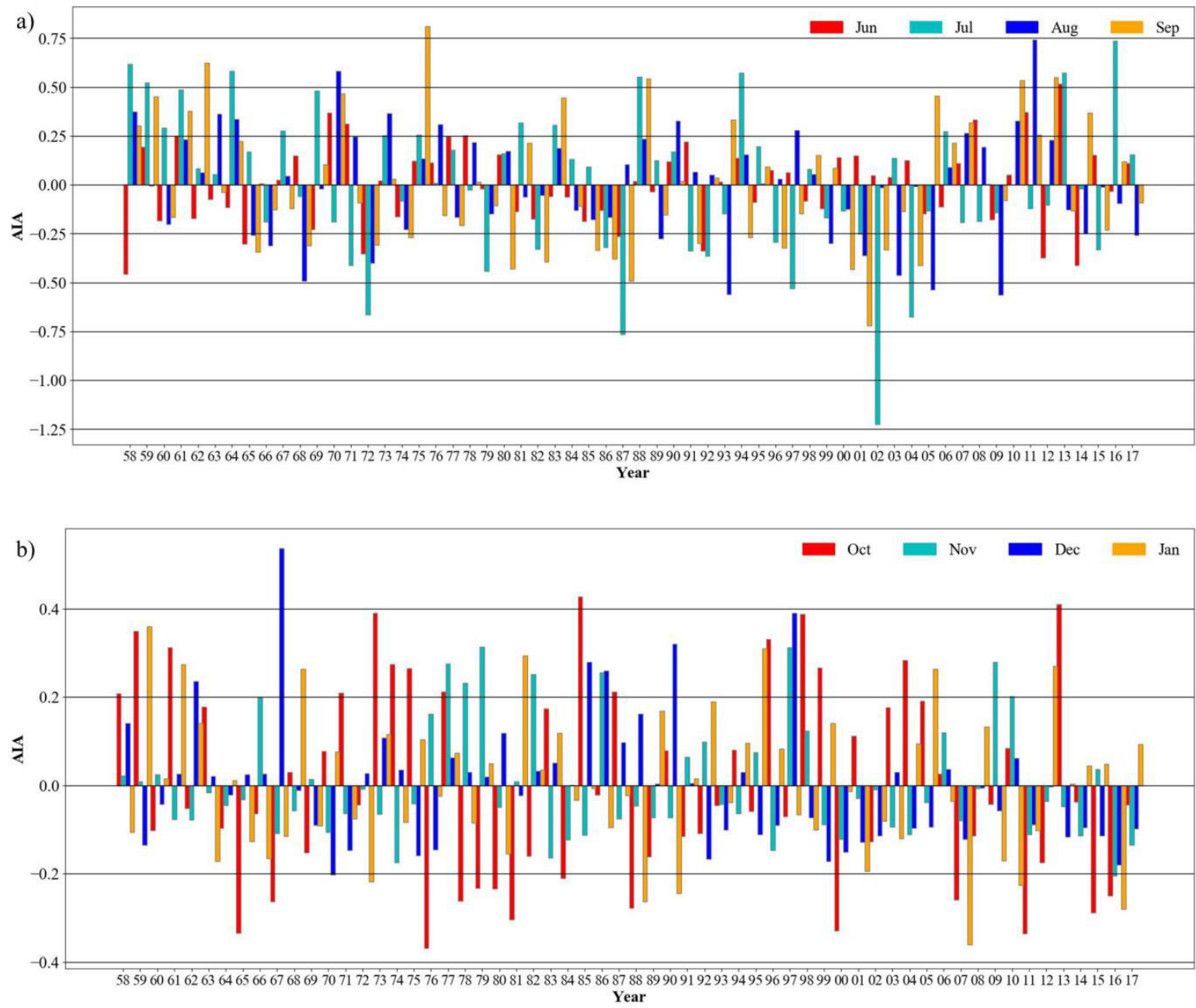


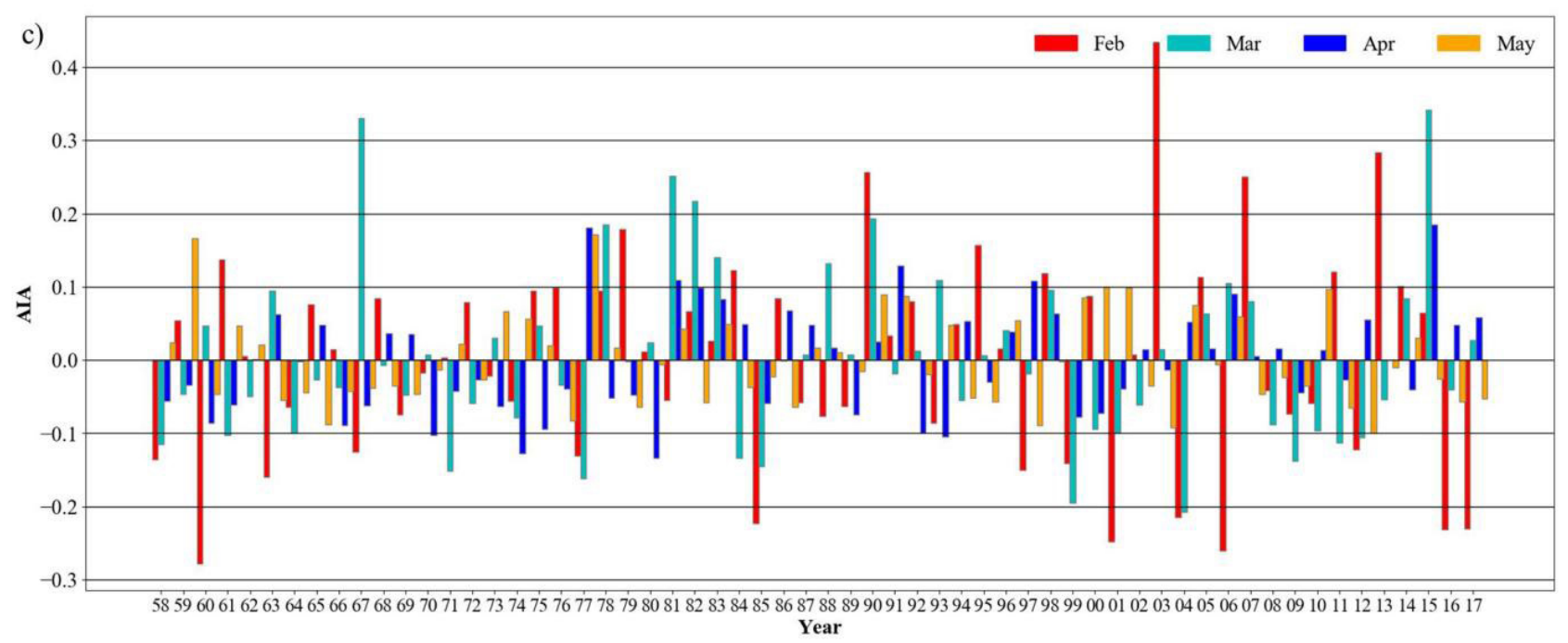

Figure 3. Monthly/seasonal pattern of AIA during 1958-2018 (a) monsoon, (b) winter, and (c) summer seasons

precipitation anomaly shows that the season-wise AIA follows the pattern with annual precipitation anomaly. The negative anomalies (AIA and precipitation anomalies) were found continued in all the seasons from 1965 to 1967 , followed by 2002-2005. The maximum impact of decline in precipitation on AIA was observed during kharif season. This was very frequent for every 4-5 years during 1972-1992. In the last few years (2013-2018) over again, the decline in precipitation had an impact on aridity of an area. The changed patterns of AI over a period in India are largely driven by the changing patterns of precipitation ${ }^{[38]}$.

\subsubsection{Spatial (monthly) change in AI}

Spatial distribution of monthly mean of AI (for 60 years) is shown in Figure 5. Distribution during January-
March shows an increasing (maximum) range of aridity levels from eastern to western part of India. In the extremely dry months (April-May), northern and central regions of India indicate characteristics of hyper-arid zone. An increasing level of humid condition is observed during wet months (June-September). Due to excess in rainfall in July-August months, these months fall under humid zones. While in October-December an increase in arid condition from south towards north-west regions is been noticed indicating dryness in the north-west part of India.

\subsubsection{Seasonal variation ( 60 years) of AIA}

The sixty years spatial distribution of AIA over India in different seasons (monsoon/kharif, winter/rabi and summer/ zaid) and annual are given Figure 6. In the monsoon, an

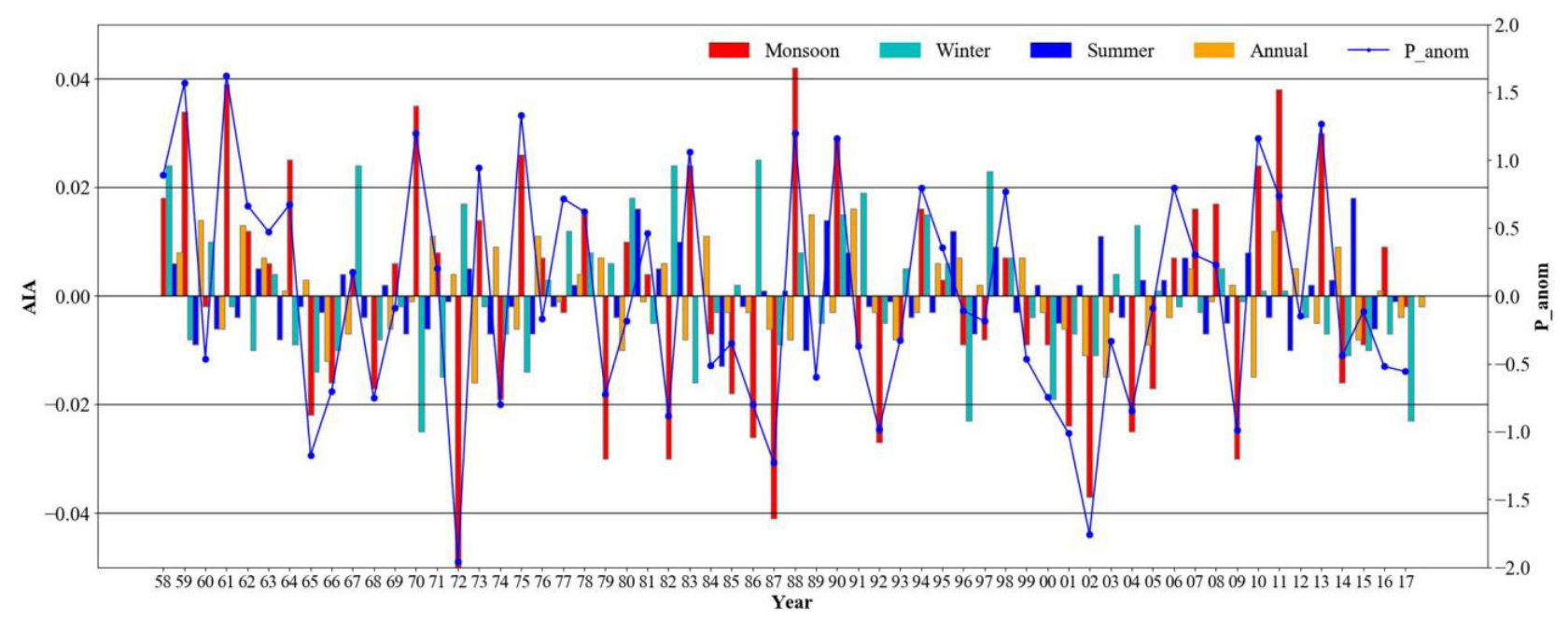

Figure 4. Long term seasonal/annual pattern of AIA with precipitation anomaly in three cropping seasons of India 

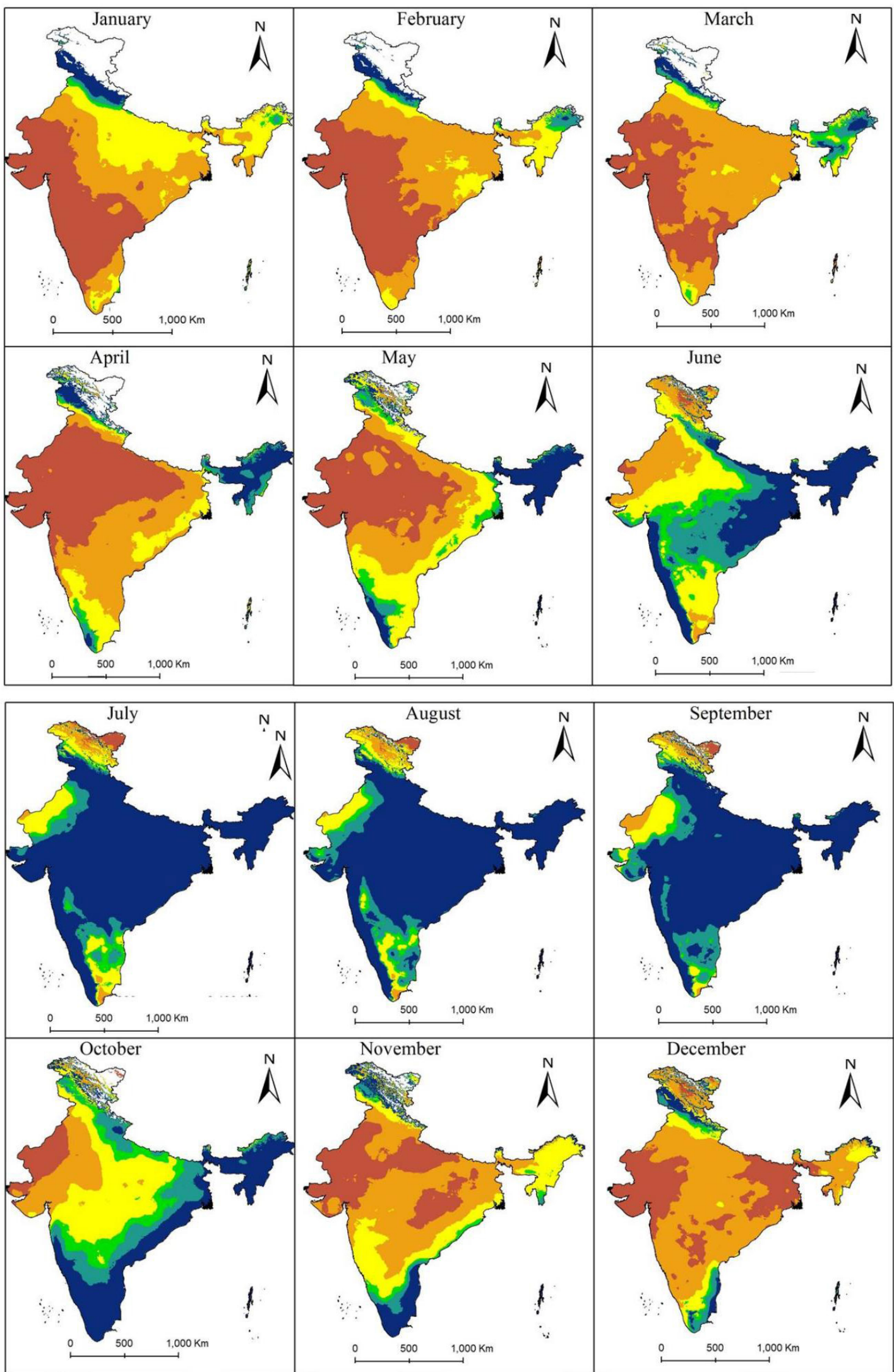

Legend

Hyper-Arid $\square$ Arid $\square$ Semi-Arid

Dry Sub-Humid

Moist Sub-Humid

Humid

Figure 5. Spatial distribution of monthly mean of 60 years AISeasonal variation (60 years) of AI 


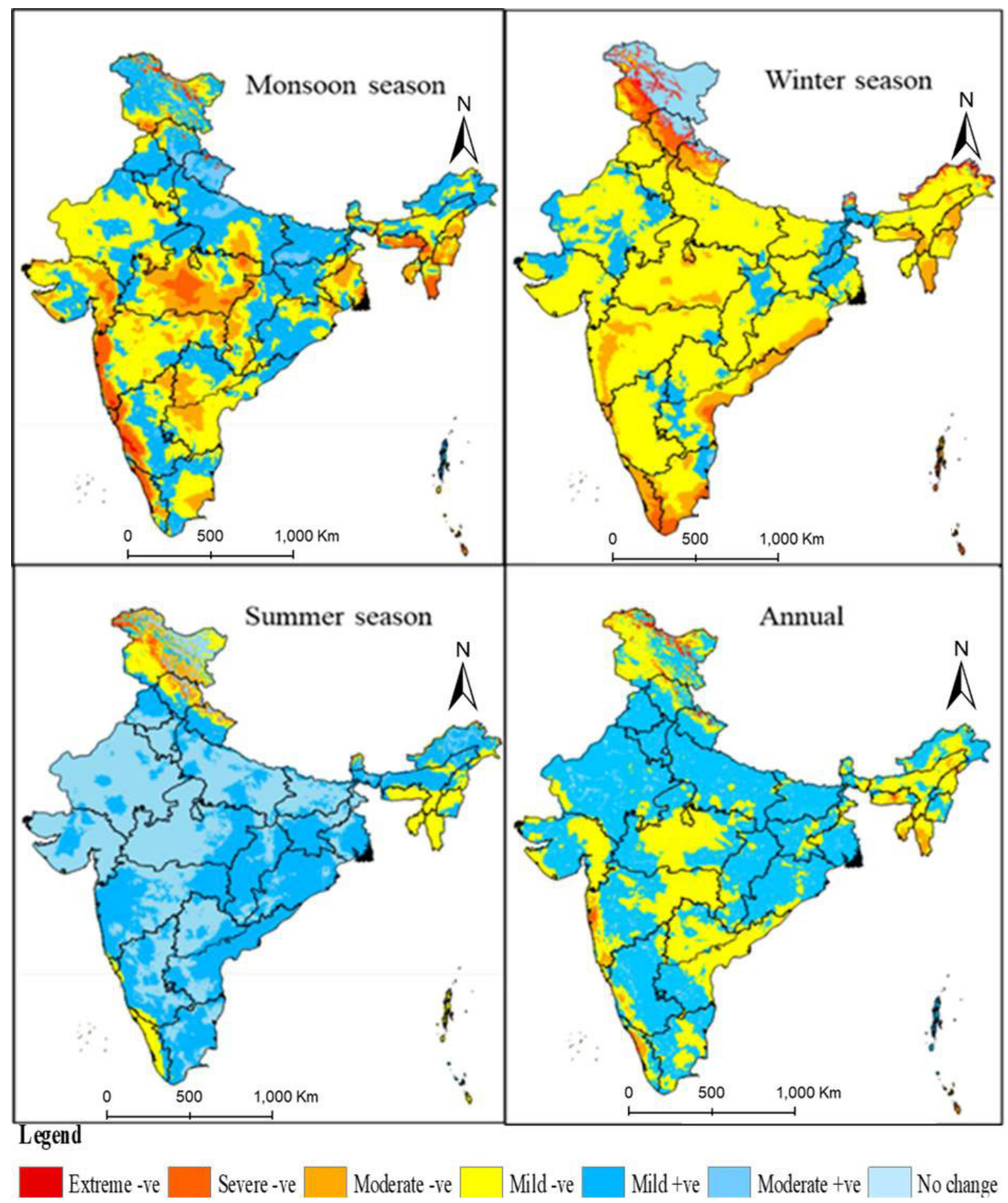

Figure 6. 60 year spatial patter of AIA for the three seasons (monsoon, winter and summer) and annual

extreme negative AIA was observed in the Western Ghats and central part of India. Whereas during winter, most of the area falls at moderate negative AIA and extremely negative is observed towards the tip and eastern costal parts of India. Overall, the annual AIA map over India shows mildly negative to moderately positive distribution.

\subsubsection{Annual aridity (1958 and 2018) analysis}

The spatial extent of change in the aridity zones over India between 1958 and 2018 is shown in Figure 7. The change in area and percentage of AI from one zone to other i.e., A-H, SA-A, DsHu-SA, DsHu-A, Hu-DsHu, and
$\mathrm{Hu}-\mathrm{SA}$ at state wise are illustrated in tabular format (Table A1). The spatially map shows, a maximum negative change of AI is towards western-central part of India, which indicates that the area is gradually shifting to dryer. The change in area percentage of aridity conditions, from $\mathrm{A}-\mathrm{H}$ and DsHu-SA are highest at Rajasthan (0.12\%) and Maharashtra (1.85\%) states. Whereas changes from SAA, DsHu-SA, and Hu-SA are high at Gujarat states (1.77 $\%, 0.03 \%$ and $1.04 \%$ ). Overall, there is a gradual increase in the extent of the arid zone during 60-year period and spatially maximum extent of change is observed at Maharashtra region. 


\subsubsection{Hot spot analysis}

The hot spot analysis tool used to identify the areas with significant spatial clustering of high variable values, is illustrated in Figure 8. The results indicate, most of the very high hot spots (statistically significant clustered areas with high negative change in AI are located at west-central part of India. State wise percentage area of hotspot computed from total geographical area of India is shown in Table A2. The maximum percentage areas of HS $99 \%$, and HS $95 \%$ confidence level is shown at Maharashtra state, indicating highly significant occurrence of change in arid condition noticed at Maharashtra, followed by Madhya Pradesh state at HS 90\% confidence. This indicates that the increase in change in extent of aridity is highest at Maharashtra region.

\subsection{Local Scale Analysis - Maharashtra}

The climatic parameters and aridity variations will have impact on agriculture. As Maharashtra is proven, highest arid change region from the section 4.1.2. Hence the study carried to assess the impact of aridity and precipitation by comparing the seasonal relationship between AIA and SPI with NDVI anomaly over Maharashtra region.

\subsubsection{AIA with NDVI anomaly}

The temporal pattern of AIA with NDVI anomaly in three seasons during 2000-2018 is illustrated in Figure 9 a-c. Frequency of occurrence of minimal to maximal range negative AIA are majority (out of 18 years, 11 years are shown negative AIA) during monsoon. Similar NDVI anomaly falls the pattern with AIA is observed over a study period, except during 20152018. Whereas, in winter season, the positive pattern of both anomalies was observed only during 2010 and 2011 followed by 2014 and 2015. During dry/ summer season, only 5 years $(2006,2011,2014,2015$ and 2018) are shown positive anomalies indicate good vegetation with residual moist condition.

\subsubsection{NDVI and SPI anomalies}

The Standardized Precipitation Index (SPI) was calculated using monthly precipitation data for 20002018 from Terra Climate. The temporal pattern of SPI with NDVI anomaly in three seasons during 2000-2018 is illustrated in Figure 10a-c. The plots of the NDVI anomalies, mostly aligns with those of the AIA and SPI temporal patters in the three seasons indicating that the

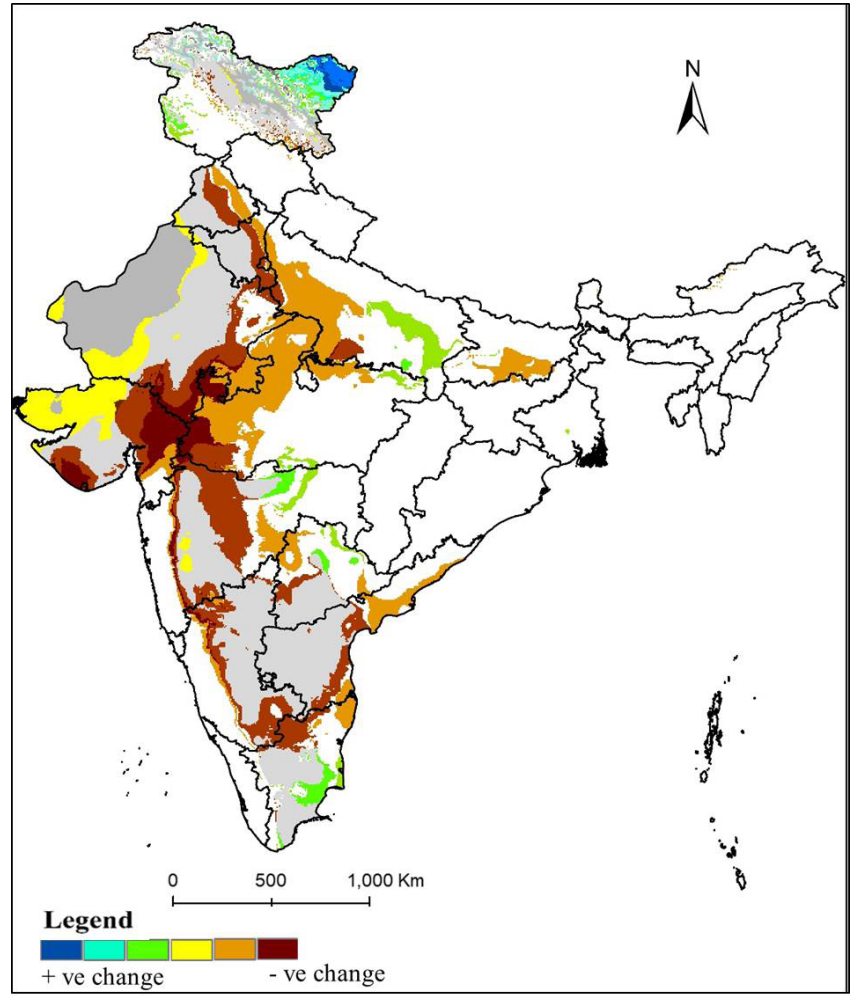

Figure 7. Changes in AI between 1958 and 2018

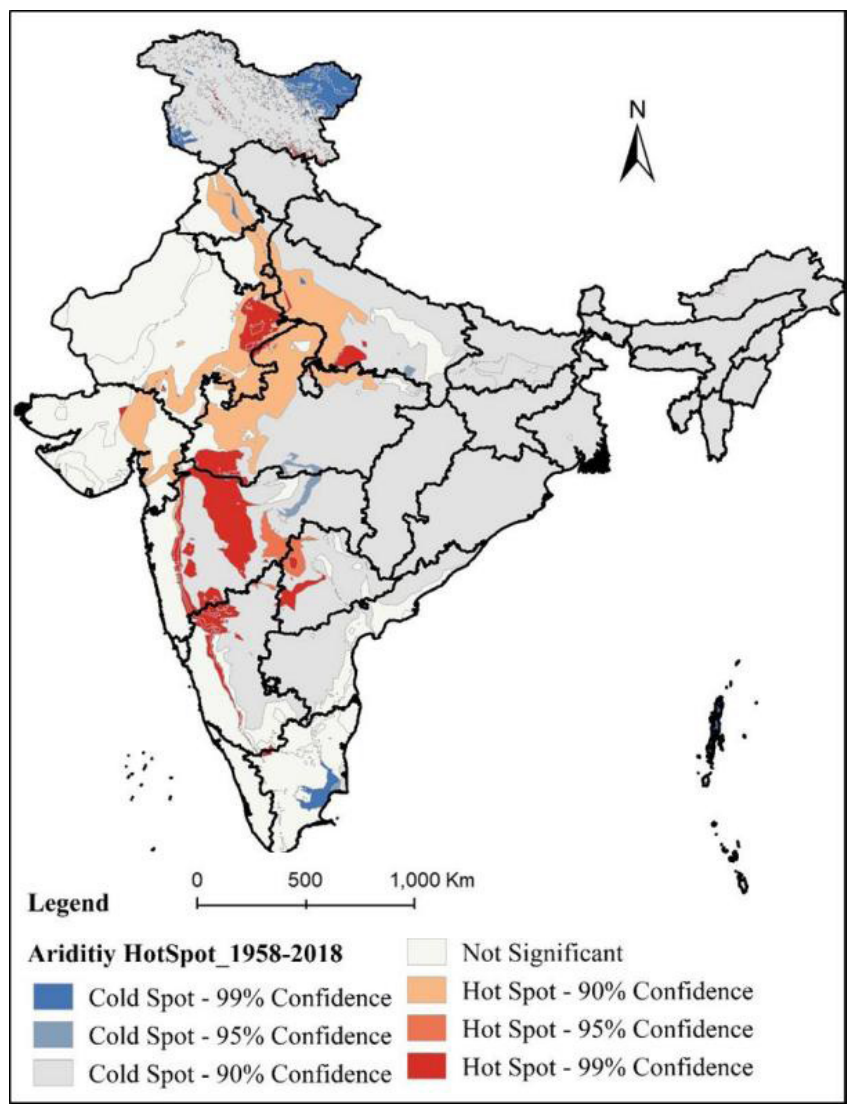

Figure 8. Spatial hotspot analysis of aridity between 1958 and 2018 

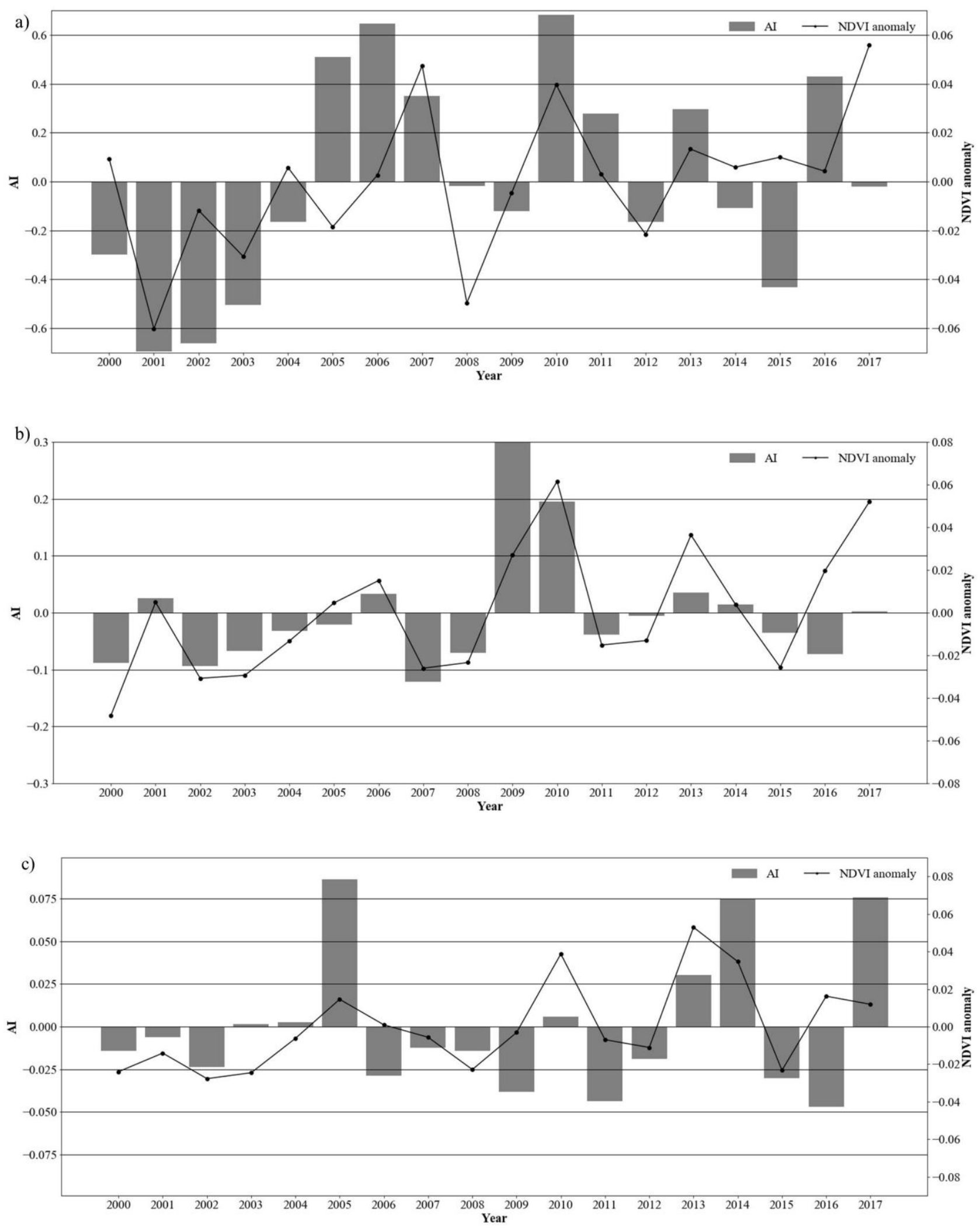

Figure 9. Temporal patterns of AI and NDVI anomaly during 2000-01 to 2017-18, (a) monsoon/kharif, (b) winter/rabi, and (c) summer/zaid season 

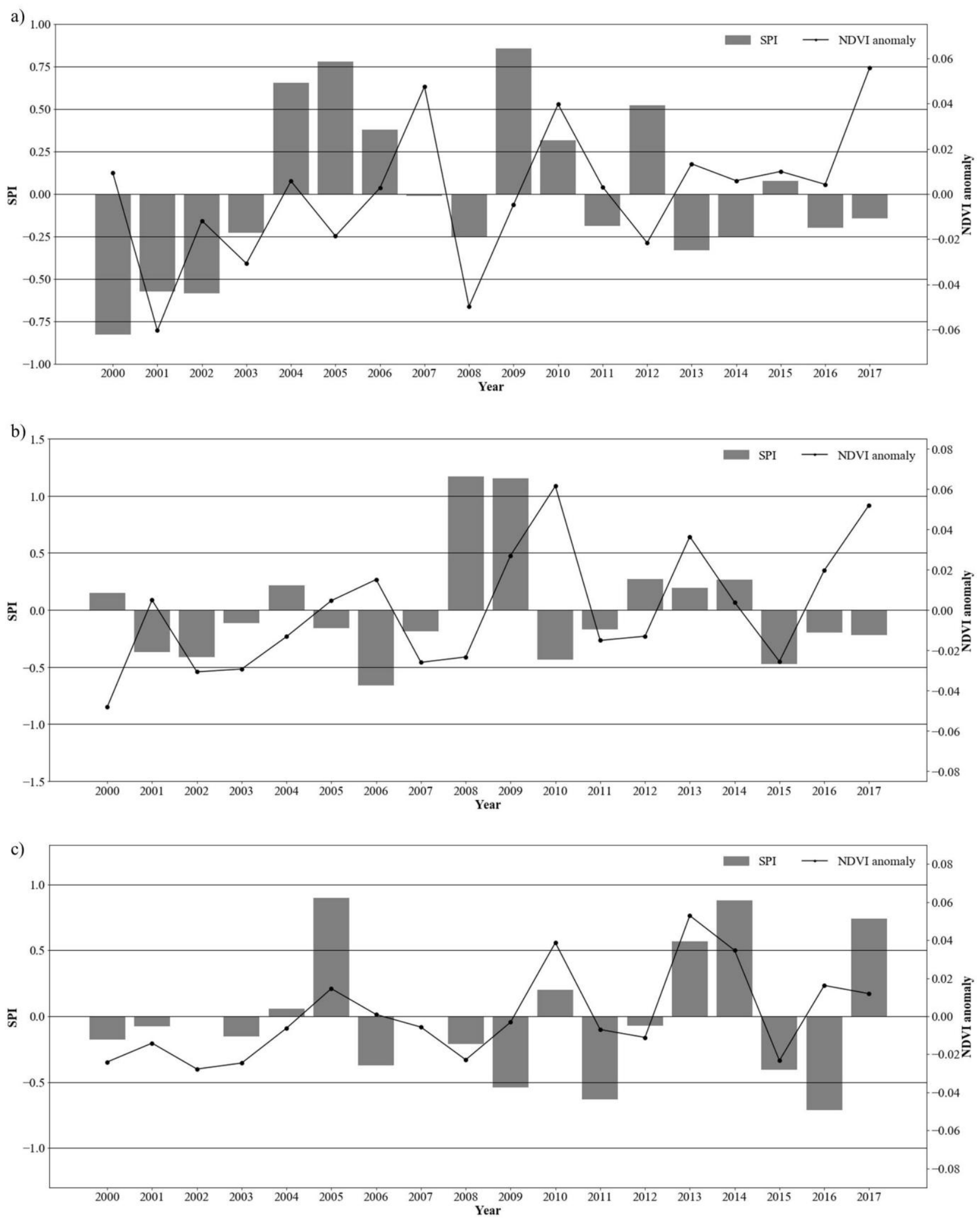

Figure 10. Temporal patterns of SPI and NDVI anomaly during 2000-01 to 2017-18,

(a) monsoon/kharif, (b) winter/rabi, and (c) summer/Zaid season 
change in vegetation is due to the precipitation and PET. However, the positive vegetation anomalies during monsoon season shown for recent years (2014 to 2017) despite there being a less precipitation, indicates that usage of available irrigation sources have been increased simultaneously. It was observed that with various major, medium, and minor irrigation projects, a total irrigation potential of 49.26 lakh ha had been created by the end of $2012^{[39]}$.

\section{Discussion}

The effective wetness or dryness of climate over a land area is decided by way of the terrestrial aridity of that area, that is measured with the aid of the ratio of annual mean precipitation to the annual imply ability evapotranspiration ${ }^{[12,13,36]}$. Earlier studies noted that globally the increase in aridity is due to the fact that the rise in atmospheric demand over land use practices leading to sever land degradation, can amplify the near-surface climatic changes and lead to further desertification over longer periods with exceed in the precipitation changes ${ }^{[40,41]}$. Thus, the degrees of dryness and the relation with precipitation carried in most of the studies to examine impacts on food grain production over India ${ }^{[38,42]}$ used coarse resolution gridded datasets. Meteorological phenomena, such as fast moving clouds, forefronts variation of solar radiation. This study addresses the research gaps of previous studies with using the fine resolution gridded data sets $\left(0.05^{\circ} \times\right.$ $\left.0.05^{\circ}\right)$ to assess the long term (1958-2018) spatio-temporal change in aridity. This also identifies the most significant hot spots and examines the relation with precipitation and arid conditions on agriculture. The results suggest that the increase in aridity may cause loss of agricultural productivity and impact the food security if mitigation actions are not initiated. More than this the findings are important to understand impacts of climate change on land use pattern, and land and water resource management.

Studying the change in aridity at the regional scale helps to understand the magnitude, identify the extreme hot spot areas and spatial pattern of the changes as well as the shift of lands from one class of aridity to another arid class. The transition of aridity is considered as a foremost and assertive impact of global climate change ${ }^{[27,43,44]}$. The study examines the sensitivity of gridded precipitation data sets for identification of semi-arid regions over India. It makes reliable assessment of the observed regional aridity changes. Such evidence is important for decision-makers as a signaling mechanism to think about adaptation planning over the semi-arid regions of India (Ramarao et al., 2018). Such assessment features the need of satisfactory planning for the water conservation during seasonal precipitation which is often overflown.
Such overflow of water during the monsoon season can be utilized for succeeding dry months. Such strategic planning can meet the harvest soil dampness request and lift horticultural creation altogether. To remedy rainfall venture and preserve crop production in the area, piloting irrigation for selected plants, as some farmers are already doing, is particularly endorsed.

\section{Conclusions}

The present study was conducted to understand the effect of recent changes in climate on aridity and shift of arid land in India between 1958 -1968 and 2008 -2018. For a regional picture across country the monthly and seasonal pattern of AI using Terra Climate (1958 -2018) data was carried out. The Terra Climate data provided trends in precipitation and PET, and these were used to assess the aridity shifts and the impact of aridly. It further focuses on aridity anomalies, drought anomalies and vegetation anomalies and the relations between them while taking a case of state of Maharashtra, India. The MODIS NDVI data were found useful while assessing NDVI anomalies along with AI and SPI. We also used data in agriculture and sources of agriculture to support our results. The incline in aridity in resulted in last 25 and 18 years during monsoon and winter seasons, whereas extreme dryness is noticed in 2002-03 year. The changed patterns of AI over a period are largely driven by the changing patterns of precipitation for every 4-5 years period. Spatial north-west portion of India shows an increase in aridity condition. Spatially variation of change in seasonal change aridity condition is observed i.e, during monsoon Western Ghats and central part of India extreme AIA and towards the tip and eastern costal parts of India in winter season.

\section{Acknowledgements}

PKB and PSR are thankful to National Academy of Sciences, India (NASI) Government of India, for the financial support and ICRISAT for the facilities and guidance.

\section{References}

[1] A.R. Sathyan, C. Funk, T. Aenis, L. Breuer, Climate Vulnerability in Rainfed Farming: Analysis from Indian Watersheds, Sustainability. 10 (2018). https://doi. org/10.3390/su10093357.

[2] DK Barik, A Need of Climate Smart and Sustainable Agriculture in India, Acta Scientific Agriculture. 3 (2019) 1-3.

[3] R.K. Mall, R. Singh, A. Gupta, G. Srinivasan, L.S Rathore, Impact of Climate Change on Indian Agriculture: A Review, Climatic Change. 78 (2006) 445-478. https://doi.org/10.1007/s10584-005-9042-x. 
[4] S. Singh, S. Nayak, CLIMATE VARIABILITY AND AGRICULTURAL PRODUCTIVITY IN UTTAR PRADESH, INDIA: EVIDENCE FROM PANEL STUDY, (2017).

[5] S. Sangkhaphan, Y. Shu, The Effect of Rainfall on Economic Growth in Thailand: A Blessing for Poor Provinces, Economies . 8 (2020). https://doi. org/10.3390/economies8010001.

[6] P.K. Thornton, P.J. Ericksen, M. Herrero, A.J. Challinor, Climate variability and vulnerability to climate change: a review, Global Change Biology. 20 (2014) 3313-3328. https://doi.org/https://doi.org/10.1111/gcb.12581.

[7] C.W. Thornthwaite, An Approach toward a Rational Classification of Climate, Geographical Review. 38 (1948) 55-94. https://doi.org/10.2307/210739.

[8] S. Sahin, An aridity index defined by precipitation and specific humidity, Journal of Hydrology. 444445 (2012) 199-208. https://doi.org/https://doi. org/10.1016/j.jhydrol.2012.04.019.

[9] M. Barzani, K. Osman Salleh, Assessment of aridity index in Iran, International Journal of Information and Decision Sciences. 9 (2017) 405. https://doi. org/10.1504/IJIDS.2017.088105.

[10] B.B. Fand, H.E.Z. Tonnang, M. Kumar, S.K. Bal, N.P. Singh, D.V.K.N. Rao, A.L. Kamble, D.D. Nangare, P.S. Minhas, Predicting the impact of climate change on regional and seasonal abundance of the mealybug Phenacoccus solenopsis Tinsley (Hemiptera: Pseudococcidae) using temperature-driven phenology model linked to GIS, Ecological Modelling. 288 (2014) 6278. https://doi.org/https://doi.org/10.1016/j.ecolmodel.2014.05.018.

[11] G. Konapala, A.K. Mishra, Y. Wada, M.E. Mann, Climate change will affect global water availability through compounding changes in seasonal precipitation and evaporation, Nature Communications. 11 (2020) 3044. https://doi.org/10.1038/s41467-020-16757-w.

[12] C. Li, P. Wu, X. Li, T. Zhou, S. Sun, Y. Wang, X. Luan, X. Yu, Spatial and temporal evolution of climatic factors and its impacts on potential evapotranspiration in Loess Plateau of Northern Shaanxi, China, Science of The Total Environment. 589 (2017). https://doi.org/10.1016/j.scitotenv.2017.02.122.

[13] M.-M. Nistor, P.K. Rai, V. Dugesar, V.N. Mishra, P. Singh, A. Arora, V.K. Kumra, I.-A. Carebia, Climate change effect on water resources in Varanasi district, India, Meteorological Applications. 27 (2020) e1863. https://doi.org/https://doi.org/10.1002/met.1863.

[14] J.T. Abatzoglou, S.Z. Dobrowski, S.A. Parks, K.C. Hegewisch, TerraClimate, a high-resolution global dataset of monthly climate and climatic water balance from 1958-2015, Scientific Data. 5 (2018) 170191. https://doi.org/10.1038/sdata.2017.191.

[15] T. Mckee, N. Doesken, J. Kleist, THE RELATIONSHIP OF DROUGHT FREQUENCY AND DURATION TO TIME SCALES, in: 1993.

[16] T.B. McKee, N.J. Doesken, J. Kleist, Drought Monitoring with Multiple Time Scales, 9th Conference, Applied climatology, in: CONFERENCE ON APPLIED CLIMATOLOGY, Applied Climatology, 9th Conference, Applied Climatology, The Society;, 1995: pp. 233-236. https://www.tib.eu/de/suchen/id/ BLCP\%3ACN008169111.

[17] State of Indian Agriculture 2015-16. https://agricoop. nic.in/sites/default/files/State_of_Indian_Agriculture\%2C2015-16.pdf.

[18] C.A. Karavitis, S. Alexandris, D.E. Tsesmelis, G. Athanasopoulos, Application of the Standardized Precipitation Index (SPI) in Greece, Water . 3 (2011). https://doi.org/10.3390/w3030787.

[19] S. Cheval, The Standardized Precipitation Index an overview, Romanian Journal of Meteorology. 12 (2015) 17-64.

[20] Jr. Rouse J. W., R. H. Haas, J. A. Schell, D. W. Deering, Monitoring Vegetation Systems in the Great Plains with Erts, in: NASA Special Publication, 1974: p. 309.

[21] K.R. Hogrefe, V.P. Patil, D.R. Ruthrauff, B.W. Meixell, M.E. Budde, J.W. Hupp, D.H. Ward, Normalized Difference Vegetation Index as an Estimator for Abundance and Quality of Avian Herbivore Forage in Arctic Alaska, Remote Sensing . 9 (2017). https:// doi.org/10.3390/rs9121234.

[22] L. Nanzad, J. Zhang, B. Tuvdendorj, M. Nabil, S. Zhang, Y. Bai, NDVI anomaly for drought monitoring and its correlation with climate factors over Mongolia from 2000 to 2016, Journal of Arid Environments. 164 (2019) 69-77. https://doi.org/https:// doi.org/10.1016/j.jaridenv.2019.01.019.

[23] A. Huete, K. Didan, T. Miura, E.P. Rodriguez, X. Gao, L.G. Ferreira, Overview of the radiometric and biophysical performance of the MODIS vegetation indices, Remote Sensing of Environment. 83 (2002) 195-213. https://doi.org/https://doi.org/10.1016/ S0034-4257(02)00096-2.

[24] B. P., C. V., P.S. Roy, P.K. Joshi, C. K., Long-term agricultural performance and climate variability for drought assessment: a regional study from Telangana and Andhra Pradesh states, India, Geomatics, Natural Hazards and Risk. 8 (2017) 822-840. https://doi.org/ 10.1080/19475705.2016.1271831.

[25] S. Measho, B. Chen, Y. Trisurat, P. Pellikka, L. Guo, S. Arunyawat, V. Tuankrua, W. Ogbazghi, T. Yemane, 
Spatio-Temporal Analysis of Vegetation Dynamics as a Response to Climate Variability and Drought Patterns in the Semiarid Region, Eritrea, Remote Sensing . 11 (2019). https://doi.org/10.3390/rs11060724.

[26] P. Páscoa, C.M. Gouveia, C. Kurz-Besson, A Simple Method to Identify Potential Groundwater-Dependent Vegetation Using NDVI MODIS, Forests . 11 (2020). https://doi.org/10.3390/f11020147.

[27] Y. Wang, C. Zhang, F.-R. Meng, C.P.-A. Bourque, C. Zhang, Evaluation of the suitability of six drought indices in naturally growing, transitional vegetation zones in Inner Mongolia (China), PLOS ONE. 15 (2020) e0233525. https://doi.org/10.1371/journal. pone. 0233525 .

[28] S.S. Kalamkar, Agricultural growth and productivity in Maharashtra: trends and determinants., Allied Publishers Private Ltd, New Delhi, 2011.

[29] S. Brahme, Drought in Maharashtra, Social Scientist. 1 (1973) 47-54. https://doi.org/10.2307/3516345.

[30] Katalakute, V. Wagh, D. Panaskar, S. Mukate, Impact of Drought on Environmental, Agricultural and Socio-economic Status in Maharashtra State, India, Natural Resources and Conservation. 4 (2016) 35-41. https://doi.org/10.13189/nrc.2016.040301.

[31] R.S. Todmal, Droughts and Agriculture in the Semi-Arid Region of Maharashtra, Western India, Weather, Climate, and Society. 11 (n.d.) 741-754. https://doi.org/10.1175/WCAS-D-18-0131.1.

[32] NIC, Maharashtra State Agricultural Portal - Software Requirement Specification. Department of Agriculture \& Cooperation, Ministry of Agriculture, Government of India, 2012. http://agricoop.nic.in/ sites/default/files/Maharashtra-SAP_V1.3-2.pdf (accessed September 9, 2020).

[33] Gore PG Ray, KC Sinha, Variability of drought incidence over districts of Maharashtra., Mausam. 53 (2002) 533-538. http://metnet.imd.gov.in/mausamdocs/25341.pdf.

[34] Mumbai. Directorate of Economics \& Statistics, Planning Department, Government of -Maharashtra, Economic Survey of Maharashtra 2019-20, 2020. https://mahades.maharashtra.gov.in/files/publication/ ESM_18_19_eng.pdf.

[35] P.S. Roy, A. Roy, P.K. Joshi, M.P. Kale, V.K. Srivastava, S.K. Srivastava, R.S. Dwevidi, C. Joshi, M.D. Behera, P. Meiyappan, Y. Sharma, A.K. Jain, J.S. Singh, Y. Palchowdhuri, Reshma.M. Ramachandran, B. Pinjarla, V. Chakravarthi, N. Babu, M.S. Gowsalya, P. Thiruvengadam, M. Kotteeswaran, V. Priya, K.M.V.N. Yelishetty, S. Maithani, G. Talukdar, I. Mondal, K.S. Rajan, P.S. Narendra, S. Biswal, A.
Chakraborty, H. Padalia, M. Chavan, S.N. Pardeshi, S.A. Chaudhari, A. Anand, A. Vyas, M.K. Reddy, M. Ramalingam, R. Manonmani, P. Behera, P. Das, P. Tripathi, S. Matin, M.L. Khan, O.P. Tripathi, J. Deka, P. Kumar, D. Kushwaha, Development of Decadal (1985-1995-2005) Land Use and Land Cover Database for India, Remote Sensing . 7 (2015). https:// doi.org/10.3390/rs70302401.

[36] UNEP, World Atlas of Desertification, 1993.

[37] D.X. Tran, F. Pla, P. Latorre-Carmona, S.W. Myint, M. Caetano, H. v Kieu, Characterizing the relationship between land use land cover change and land surface temperature, ISPRS Journal of Photogrammetry and Remote Sensing. 124 (2017) 119-132. https://doi.org/ https://doi.org/10.1016/j.isprsjprs.2017.01.001.

[38] M. Ramarao, J. Sanjay, K. Raghavan, M. Mujumdar, A. Bazaz, A. Revi, On observed aridity changes over the semiarid regions of India in a warming climate, Theoretical and Applied Climatology. 136 (2019) 1-10. https://doi.org/10.1007/s00704-018-2513-6.

[39] P.V. Salve, A socio economic study of irrigation projects in Maharashtra state with special reference to marathwada region., (2016). http://shodhganga. inflibnet.ac.in:8080/jspui/handle/10603/305734\#.

[40] A. Berg, K. Findell, B. Lintner, A. Giannini, S.I. Seneviratne, B. van den Hurk, R. Lorenz, A. Pitman, S. Hagemann, A. Meier, F. Cheruy, A. Ducharne, S. Malyshev, P.C.D. Milly, Land-atmosphere feedbacks amplify aridity increase over land under global warming, Nature Climate Change. 6 (2016) 869-874. https://doi.org/10.1038/nclimate3029.

[41] P. D'Odorico, A. Bhattachan, K.F. Davis, S. Ravi, C.W. Runyan, Global desertification: Drivers and feedbacks, Advances in Water Resources. 51 (2013) 326-344. https://doi.org/https://doi.org/10.1016/j.advwatres.2012.01.013.

[42] L. Goparaju, F. Ahmad, Analysis of Seasonal Precipitation, Potential Evapotranspiration, Aridity, Future Precipitation Anomaly and Major Crops at District Level of India, KN - Journal of Cartography and Geographic Information. 69 (2019) 143-154. https:// doi.org/10.1007/s42489-019-00020-4.

[43] M.R. Houmsi, M.S. Shiru, M.S. Nashwan, K. Ahmed, G.F. Ziarh, S. Shahid, E.-S. Chung, S. Kim, Spatial Shift of Aridity and Its Impact on Land Use of Syria, Sustainability . 11 (2019). https://doi. org/10.3390/su11247047.

[44] S. Hadipour, A.K. Abd Wahab, S. Shahid, Spatiotemporal changes in aridity and the shift of drylands in Iran, Atmospheric Research. 233 (2019). https://doi. org/10.1016/j.atmosres.2019.104704. 


\section{Supplementary Material}

\section{Spatial pattern of dryness}

The spatial extent of dryness is computed by differencing two different years' annual AI mean images.
The map is categorized into 5 classes based of degree of dryness. In 1958 to 2000 , the major extreme to dry classes has been observed at west to central part of India, followed by eastern part of India. In 1958 to 2018, the maximum extent of dryness is observed towards west part of India (Gujarat).
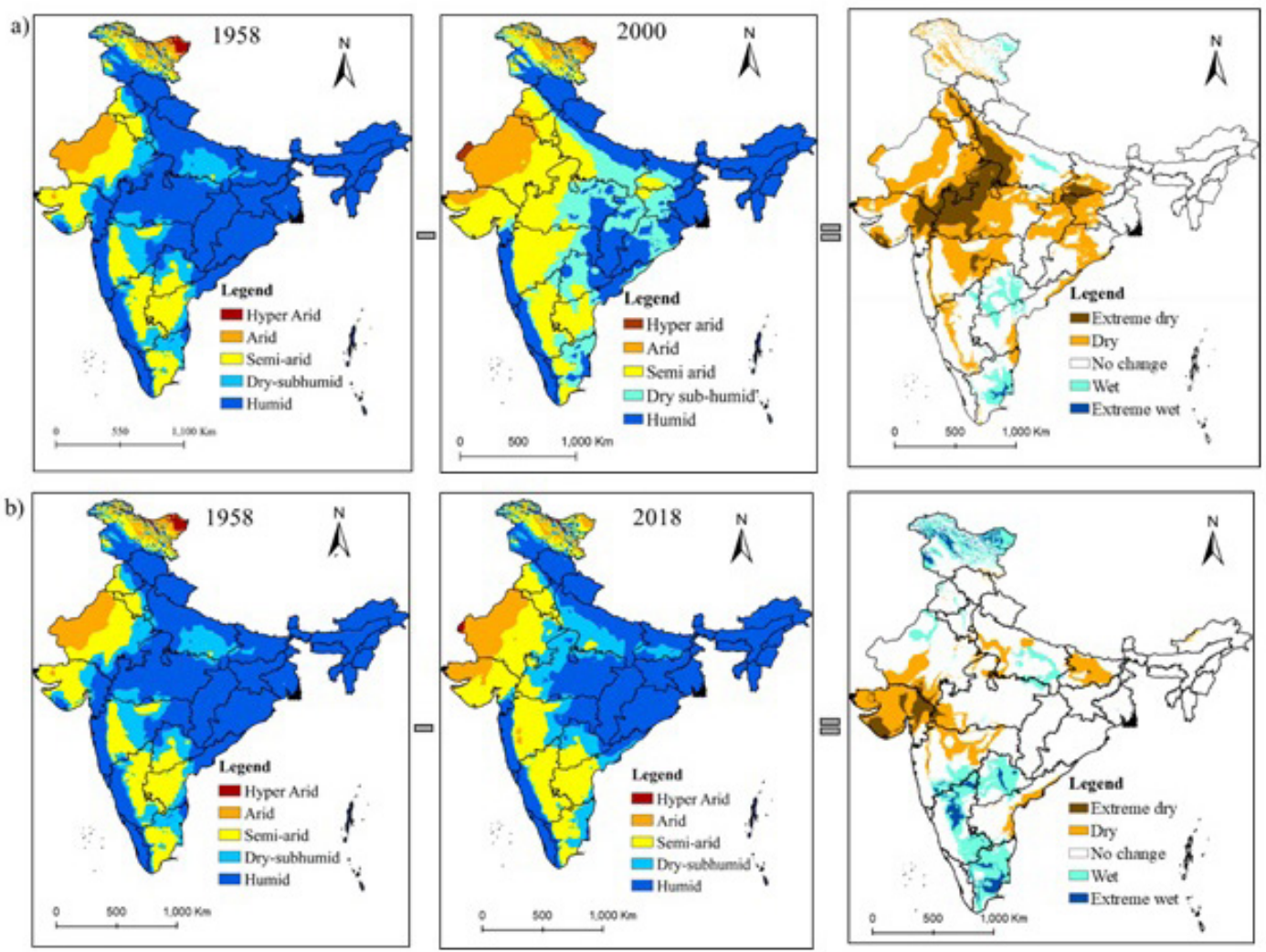

Figure A1. Spatial distribution of extent of dryness maps (a) 1958, 2002 and difference of 1958-2000, and b) 1958, 2018 and difference of 1958-2018

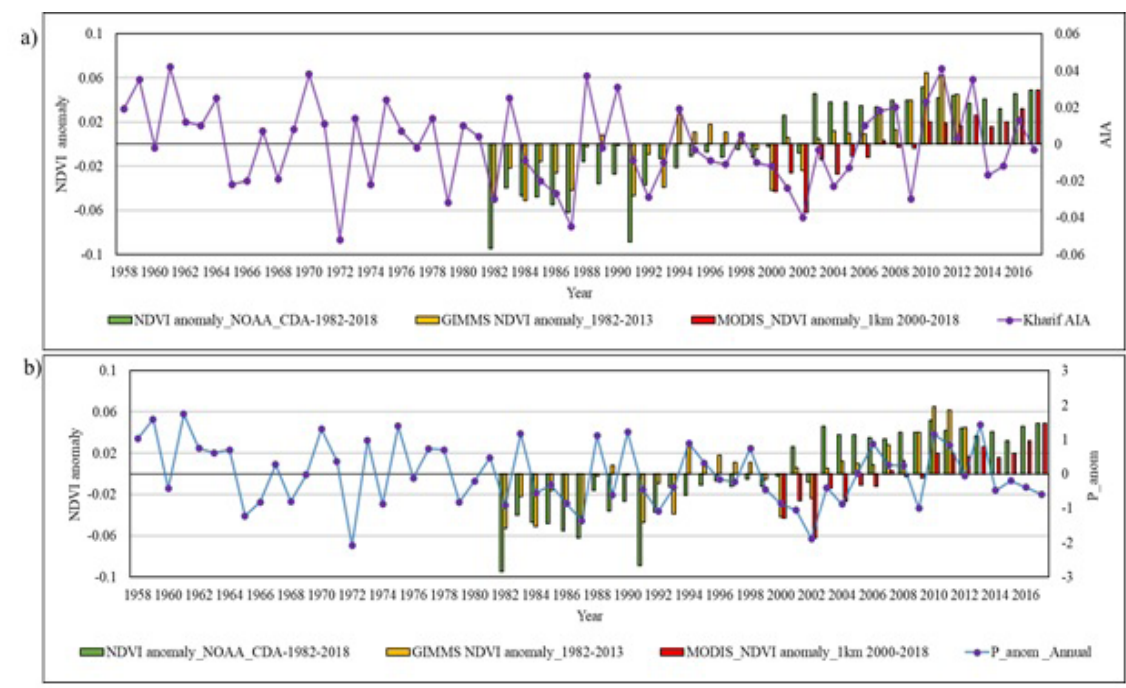

Figure A2. Long term seasonal pattern of (a) Kharif season AIA with NDVI anomaly for 1958-2018, and (b) annual precipitation anomaly with Kharif season inter-sensor NDVI anomaly 
Table A1. State wise percentage change in AI classes

\begin{tabular}{|c|c|c|c|c|c|}
\hline States Names & A-HA & SA-A & DsHu-SA & DsHu-A & Hu-SA \\
\hline Andaman and Nicobar & 0.00 & 0.00 & 0.00 & 0.00 & 0.00 \\
\hline Andhra Pradesh & 0.00 & 0.00 & 0.79 & 0.00 & 0.01 \\
\hline Arunachal Pradesh & 0.00 & 0.00 & 0.00 & 0.00 & 0.00 \\
\hline Assam & 0.00 & 0.00 & 0.00 & 0.00 & 0.00 \\
\hline Bihar & 0.00 & 0.00 & 0.00 & 0.00 & 0.00 \\
\hline Chandigarh & 0.00 & 0.00 & 0.00 & 0.00 & 0.00 \\
\hline Chhattisgarh & 0.00 & 0.00 & 0.00 & 0.00 & 0.00 \\
\hline Dadra and Nagar Haveli & 0.00 & 0.00 & 0.00 & 0.00 & 0.00 \\
\hline Daman and Diu & 0.00 & 0.00 & 0.01 & 0.00 & 0.01 \\
\hline Delhi & 0.00 & 0.00 & 0.02 & 0.00 & 0.00 \\
\hline Goa & 0.00 & 0.00 & 0.00 & 0.00 & 0.00 \\
\hline Gujarat & 0.00 & $1.77 *$ & 1.08 & $0.03 *$ & $1.04 *$ \\
\hline Haryana & 0.00 & 0.03 & 0.31 & 0.00 & 0.00 \\
\hline Himachal Pradesh & 0.00 & 0.00 & 0.00 & 0.00 & 0.00 \\
\hline Jammu and Kashmir & 0.00 & 0.04 & 0.11 & 0.00 & 0.00 \\
\hline Jharkhand & 0.00 & 0.00 & 0.00 & 0.00 & 0.00 \\
\hline Karnataka & 0.00 & 0.00 & 1.11 & 0.00 & 0.10 \\
\hline Kerala & 0.00 & 0.00 & 0.00 & 0.00 & 0.00 \\
\hline Madhya Pradesh & 0.00 & 0.00 & 0.46 & 0.00 & 0.60 \\
\hline Maharashtra & 0.00 & 0.13 & $1.85^{*}$ & 0.00 & 0.19 \\
\hline Manipur & 0.00 & 0.00 & 0.00 & 0.00 & 0.00 \\
\hline Meghalaya & 0.00 & 0.00 & 0.00 & 0.00 & 0.00 \\
\hline Mizoram & 0.00 & 0.00 & 0.00 & 0.00 & 0.00 \\
\hline Nagaland & 0.00 & 0.00 & 0.00 & 0.00 & 0.00 \\
\hline Orissa & 0.00 & 0.00 & 0.00 & 0.00 & 0.00 \\
\hline Pondicherry & 0.00 & 0.00 & 0.00 & 0.00 & 0.00 \\
\hline Punjab & 0.00 & 0.04 & 0.35 & 0.00 & 0.00 \\
\hline Rajasthan & $0.12 *$ & 0.97 & 1.23 & 0.00 & 0.51 \\
\hline Sikkim & 0.00 & 0.00 & 0.00 & 0.00 & 0.00 \\
\hline Tamil Nadu & 0.00 & 0.00 & 0.51 & 0.00 & 0.00 \\
\hline Tripura & 0.00 & 0.00 & 0.00 & 0.00 & 0.00 \\
\hline Uttar Pradesh & 0.00 & 0.00 & 0.27 & 0.00 & 0.01 \\
\hline Uttaranchal & 0.00 & 0.00 & 0.00 & 0.00 & 0.00 \\
\hline West Bengal & 0.00 & 0.00 & 0.00 & 0.00 & 0.00 \\
\hline India & 0.12 & 2.98 & 8.10 & 0.03 & 2.46 \\
\hline
\end{tabular}

HA - Hyper-arid; A - Arid; SA - Semi-Arid; DsHu - Dry sub-Humid; Hu - Humid

*Highest values among all states 
Table A2. State wise area Percentage of hot spot

\begin{tabular}{|c|c|c|c|c|c|c|c|}
\hline \multirow{2}{*}{ State Names } & \multicolumn{7}{|c|}{ Area Percentage of hot spot } \\
\hline & CS_99\% & CS_95\% & CS_90\% & No Change & HS_90\% & HS_95\% & HS_99\% \\
\hline Andaman and Nicobar & 0.15 & 0.00 & 0.05 & 0.00 & 0.00 & 0.00 & 0.00 \\
\hline Andhra Pradesh & 0.00 & 0.00 & 6.20 & 1.64 & 0.00 & 0.28 & 0.25 \\
\hline Arunachal Pradesh & 0.00 & 0.00 & 2.57 & 0.00 & 0.00 & 0.00 & 0.01 \\
\hline Assam & 0.00 & 0.00 & 2.46 & 0.00 & 0.00 & 0.00 & 0.00 \\
\hline Bihar & 0.00 & 0.00 & 2.86 & 0.02 & 0.00 & 0.00 & 0.01 \\
\hline Chandigarh & 0.00 & 0.00 & 0.00 & 0.00 & 0.00 & 0.00 & 0.00 \\
\hline Chhattisgarh & 0.00 & 0.00 & 4.12 & 0.00 & 0.00 & 0.00 & 0.00 \\
\hline Dadra and Nagar Haveli & 0.00 & 0.00 & 0.00 & 0.02 & 0.00 & 0.00 & 0.00 \\
\hline Daman and Diu & 0.00 & 0.00 & 0.00 & 0.02 & 0.00 & 0.00 & 0.00 \\
\hline Delhi & 0.00 & 0.01 & 0.00 & 0.00 & 0.04 & 0.00 & 0.00 \\
\hline Goa & 0.00 & 0.00 & 0.00 & 0.11 & 0.00 & 0.00 & 0.00 \\
\hline Gujarat & 0.00 & 0.00 & 0.00 & 4.76 & 0.94 & 0.00 & 0.04 \\
\hline Haryana & 0.01 & 0.00 & 0.13 & 0.78 & 0.43 & 0.00 & 0.00 \\
\hline Himachal Pradesh & 0.00 & 0.00 & 1.68 & 0.00 & 0.00 & 0.00 & 0.02 \\
\hline Jammu and Kashmir & 1.39 & 0.02 & 4.97 & 0.07 & 0.00 & 0.01 & 0.16 \\
\hline Jharkhand & 0.00 & 0.00 & 2.46 & 0.00 & 0.00 & 0.00 & 0.00 \\
\hline Karnataka & 0.00 & 0.00 & 2.81 & 2.35 & 0.00 & 0.05 & 0.66 \\
\hline Kerala & 0.00 & 0.00 & 0.00 & 1.15 & 0.00 & 0.00 & 0.00 \\
\hline Madhya Pradesh & 0.00 & 0.11 & 5.02 & 0.82 & 2.88 & 0.01 & 0.55 \\
\hline Maharashtra & 0.00 & 0.17 & 4.83 & 1.77 & 0.09 & $0.35^{*}$ & $2.21^{*}$ \\
\hline Manipur & 0.00 & 0.00 & 0.71 & 0.00 & 0.00 & 0.00 & 0.00 \\
\hline Meghalaya & 0.00 & 0.00 & 0.70 & 0.00 & 0.00 & 0.00 & 0.00 \\
\hline Mizoram & 0.00 & 0.00 & 0.66 & 0.00 & 0.00 & 0.00 & 0.00 \\
\hline Nagaland & 0.00 & 0.00 & 0.53 & 0.00 & 0.00 & 0.00 & 0.00 \\
\hline Orissa & 0.00 & 0.00 & 4.75 & 0.00 & 0.00 & 0.00 & 0.00 \\
\hline Pondicherry & 0.00 & 0.00 & 0.00 & 0.01 & 0.00 & 0.00 & 0.00 \\
\hline Punjab & 0.03 & 0.01 & 0.21 & 0.69 & 0.61 & 0.00 & 0.00 \\
\hline Rajasthan & 0.00 & 0.00 & 0.00 & 8.07 & 1.82 & 0.01 & 0.65 \\
\hline Sikkim & 0.00 & 0.00 & 0.22 & 0.00 & 0.00 & 0.00 & 0.00 \\
\hline Tamil Nadu & 0.32 & 0.03 & 0.10 & 3.49 & 0.00 & 0.00 & 0.02 \\
\hline Tripura & 0.00 & 0.00 & 0.32 & 0.00 & 0.00 & 0.00 & 0.00 \\
\hline Uttar Pradesh & 0.01 & 0.04 & 4.52 & 0.73 & 1.79 & 0.01 & 0.24 \\
\hline Uttaranchal & 0.00 & 0.00 & 1.62 & 0.00 & 0.00 & 0.00 & 0.00 \\
\hline West Bengal & 0.00 & 0.00 & 2.56 & 0.01 & 0.00 & 0.00 & 0.00 \\
\hline
\end{tabular}

C - Cold Spot; HS - Hot Spot and value \% is significant level.

*Highest values among all states 